\title{
The use of patients for learning and maintaining practical skills
}

\author{
S M Yentis MD FRCA
}

J R Soc Med 2005;98:299-302

Throughout their careers, doctors have an ethical obligation to consider the benefits and harms of treatment, and choose the most appropriate for each patient, resources allowing. There is also a legal requirement to practise to acceptable standards together with a professional requirement to participate in continuous medical education/professional development. The General Medical Council (GMC) states 'Doctors are responsible for maintaining their professional competence and standard of performance . . .' ' and 'You must keep your knowledge and skills up to date . . .' ' There is a corresponding duty to educate others: 'You should be willing to contribute to the education of students or colleagues.' 2

A doctor's prime duty, however, is to 'Make the care of your patient your first concern'2_ a duty that sits awkwardly with the other duty to learn and maintain less familiar skills that might be required for other patients. This conflict has implications for respecting patients' autonomy, gaining consent for treatments and upholding standards of practice. For example, fear of complaint or legal action motivates many anaesthetists specifically interested in airway management to stop teaching others on procedures or maintaining their own skills (debate and discussion, Difficult Airway Society Annual Meetings, Edinburgh 1999 and London 2002), despite recognized deficiencies in these skills. ${ }^{3}$ Most of their concerns relate to informed consent for specific procedures or parts thereof - even though many consider them 'routine'. Such concerns may not be unwarranted: there are discrepancies between what patients would wish to be informed about and what anaesthetists feel they should be informed about. ${ }^{4}$

The published work tends to neglect this dilemma, instead focusing on junior trainees, medical students, or practice on the recently dead, ${ }^{5-7}$ but it merits wide debate especially at a time when specialist training is being curtailed and new consultants will be short of practical experience..$^{8,9}$

Here I discuss the following questions. What is a 'procedure' and how can one decide whether its components can or should be considered separately-for example, regarding consent and choice? How can doctors

Magill Department of Anaesthesia, Intensive Care and Pain Management, Chelsea \& Westminster Hospital, 369 Fulham Road, London SW10 9NH, UK E-mail: s.yentis@imperial.ac.uk balance their obligations to the present patient with those to future patients and society? Do patients themselves have obligations to other patients such that they ought to participate in doctors' learning or maintenance of skills? And how can the practitioner reconcile these conflicts while respecting patients' autonomy? Finally, I offer a stepwise, practical approach based on consideration of these questions.

\section{PROCEDURES}

\section{Complexity}

A crucial question is, what constitutes a 'procedure'? From the patient's perspective, for example, hip replacement is the removal of the worn joint and insertion of a new one. From the anaesthetist's viewpoint, the following might all be considered separate procedures: intravenous cannulation; epidural insertion; induction of anaesthesia; tracheal intubation and extubation. Furthermore, many of these are complex; epidural insertion may be midline or paramedian, each with particular advantages/disadvantages, and tracheal intubation may involve 'standard' laryngoscopes, alternatively shaped blades, or flexible fibrescopes (generally reserved for difficult cases but possibly less traumatic in routine cases). The anaesthetist, moreover, might consider surgery a single 'procedure' whereas the surgeon might subdivide it into skin incision, superficial/deep dissection, removal of diseased bone, preparation of the remaining bone, insertion of the prosthesis, and closure. Doubtless many further subdivisions are possible.

Such precision may seem pedantic but it has great relevance to whether patients should, or can, consent to each component of a greater 'procedure'. Other important aspects are the benefits and harm that might result.

\section{Benefits}

The degree of benefit will vary from procedure to procedure and, often, with practitioners' experience. With proper supervision, inexperienced practitioners should be able to provide at least adequate benefit, however defined. It is even possible that greater benefit could result from supervised procedures, because of closer scrutiny and greater attention to detail. In some cases, practitioners' experience has little impact unless the procedure fails. For 
example, once tracheal intubation is accomplished, its entire benefit has been achieved - though the amount of harm caused while achieving it may vary with experience (see below).

Future patients also benefit from what the doctor learns when performing the procedure. For common procedures such as venous cannulation there are many future beneficiaries; for others such as fibreoptic intubation there are fewer although the magnitude of benefit for each may be huge: when standard intubation fails, fibreoptic intubation can be life-saving. Though novice practitioners have most to learn, even fully fledged specialists learn from each clinical encounter since every patient differs slightly from the last.

\section{Harms}

Few procedures are risk-free and patients may experience apprehension, discomfort or specific complications. Treatment by inexperienced practitioners may increase the risks although (as stated above) not necessarily. An important but abstract harm is disrespect for autonomy, if patients are 'used' for teaching or training without consent. ${ }^{10,11}$ Moreover, if patients fear that their doctor might be driven by interests other than their wellbeing, doctor-patient trust will suffer (though it would also suffer if doctors were unable to learn adequately). If patients agree to participate, autonomy is respected, but it is unethical to treat people merely as means to an end. Others may also suffer harme.g. the institution - if complications occur, and harm may befall future patients if doctors learn bad techniques.

\section{AUTONOMY, CONSENT AND CHOICE}

Autonomy's central place in medical ethics is reflected in the professional and legal emphasis on informed consent. ${ }^{12,13}$ An extension of the patient-centred approach is the promotion of patients' 'choice', currently dominating the political agenda. ${ }^{14}$ However, the extent to which consent can be 'informed' is open to question, and choice and autonomy are not the same thing.

The complexity of medical treatments makes it difficult, perhaps impossible, for patients to give truly informed consent. ${ }^{15}$ A practical procedure that includes multiple components cannot be explained in its entirety since the level of detail is potentially endless. Furthermore, if every clinical encounter has educational potential, then the presence of both therapeutic and educational components adds a further layer of complexity. Such difficulties are reflected in the vagueness of the guidance that exists: neither the GMC nor the Department of Health covers this aspect of treatment. ${ }^{12,13,16}$ Regarding anaesthesia, professional guidance published in 1999 suggests that consent includes consent for its components too, ${ }^{17}$ and this would appear to be supported by case law_-albeit established over ten years ago. ${ }^{18}$ The Royal College of Anaesthetists has advised that consent is unnecessary for fibreoptic intubation performed by trainees under supervision if the procedure would 'normally' be used; procedures not 'normally' used are 'probably' inappropriate for teaching purposes. ${ }^{19}$ However, these terms are not defined, the guidance is brief and lacking in detail, and the suggested referral to a clinical ethics committee is unhelpful since most hospitals do not have one. ${ }^{20}$

It is commonly assumed that allowing choice is the same thing as respecting autonomy and that by promoting the former one is respecting the latter-or conversely, by denying patients choice one is disrespecting their autonomy. However, in order to make an autonomous decision one does not require multiple options (for example, one does not need six restaurants to decide whether to eat out). ${ }^{21}$ Patients are already denied choice at several levels (e.g. which services are offered by their local hospital; which ward they go to; which drug is used to induce anaesthesia) without obvious breaches of their autonomy. Furthermore, the choice between two options is not an autonomous decision if the agent is not fully informed about each, ${ }^{21}$ and it could be argued that patients are already making (and must continue to make) nonautonomous decisions about procedures because of the difficulties described above.

\section{OBLIGATIONS \\ Doctors}

Doctors should not feel they must completely exhaust their primary obligations to the patient before paying any attention to societal obligations, so long as the care the patient receives is acceptable. Thus care might sometimes be pinned to this minimal acceptable standard in order to fulfil societal obligations, e.g. resource allocation, preventive medicine or research. ${ }^{10}$ Doctors' societal obligations must, however, be weighed against resultant individual harms, particularly regarding autonomy. ${ }^{10,11} \mathrm{~A}$ cautious approach is generally advocated; for example, though doctors must sometimes recognize a public duty to breach medical confidentiality, the circumstances in which disclosure is permissible are carefully restricted. ${ }^{22,23}$ This caution reflects the recognition of patients' vulnerability and rights, and the balance between the benefits/harms of such actions.

\section{Patients}

It has been argued that patients have obligations to participate in training. From a consequentialist viewpoint, in which individuals must do whatever maximizes the good and minimizes the harm, patients are obliged to participate 
since any harms they might experience are outweighed by the benefits to countless future recipients of the skills learnt. Such an argument, though, is incompatible with the modern emphasis on autonomy. ${ }^{11}$ Furthermore, the resultant damage to doctor-patient trust would reduce or even negate the overall good of such a policy. Alternatively, patients' participation might 'repay a debt' to past patients who have contributed to the teaching of current doctors. However, yesterday's patients cannot benefit directly and not all have contributed - nor do all today's patients have the opportunity to 'repay' them. ${ }^{24}$

A more convincing argument is one based on individuals' place in a continuing society and their obligations to it and to other members of that societyboth present and future. ${ }^{25}$ This communitarian approach is supported by the principles ${ }^{11}$ of beneficence (it's good that my actions benefit others), non-maleficence (it's wrong if they harm others), and justice (it's unfair to insist that my wishes be satisfied to the detriment of others') - even though individuals' autonomy might be compromised. ${ }^{26}$

Patients' obligations to others are recognized and accepted in other areas of medicine-for example, the duties to give blood and carry an organ donor card. ${ }^{27}$ However, these obligations are not strong enough to override all other considerations and the general view is that, if such obligations exist, autonomy should not be compromised in order to meet them. ${ }^{11}$

\section{OPTIONS AND SOLUTIONS}

\section{The research model}

It has been proposed that consent for training should follow the process for consent for research, in view of their similarities. ${ }^{28,29}$ Training and research are both extra to 'therapeutic' care yet necessary for medicine's continuation and improvement; individuals may volunteer altruistically as subjects for both; and both require protection for vulnerable patients. Application of the research model to learning/maintaining practical skills recognizes these common features and capitalizes on the voluminous guidance for the regulation of research. As in research, training would be based around fully informed consentparticularly concerning the extra risk and the lack of any obligation to participate. ${ }^{28,29}$

Certain differences limit the appropriateness of this model. Even in therapeutic research, individuals do not participate primarily to derive benefit, which cannot be guaranteed. But patients undergoing therapeutic procedures are expected to benefit, notwithstanding attendant risks. Second, therapeutic research involves processes extra to patients' care whereas most training experiences occur during it. Finally, patients consent to research separately from treatment, but since the educational and therapeutic components of procedures cannot easily be distinguished, the obtaining of separate consent for educational aims becomes near impossible-except for procedures performed solely for educational purposes.

\section{A practical approach}

I propose a stepwise practical approach (Box 1). For example, a novice would be unjustified in using fibreoptic intubation without consent in a routine case, since the harms (infringing autonomy, prolonging intubation, damaging the fibrescope) outweigh the benefits; furthermore, there are alternatives for training (e.g. courses) and for intubation ('standard' technique). Even were the patient's autonomy respected by prior consent, the harms arguably outweigh the benefits.

Box 1 Stepwise approach to be followed whenever seeking consent for practical procedures in which there is potential for learning on the part of the practitioner and/or observers

1. Recognize the patient's rights, the importance of autonomy and how these are vulnerable to infringement

2. Consider both the magnitude and the likelihood of benefits and harms that might accrue to the patient, to other/future patients and to society. This requires the educational content of the procedure to be identified and defined, as much as possible. The needs and condition of the particular patient, the nature of the procedure itself, and the expertise of the practitioner(s) would all contribute to this analysis

3. Consider how the benefits might be maximized and the harms minimized, both for each particular procedure and in general terms-for example, by developing efficient training programmes, ensuring that training opportunities are not 'wasted' on inappropriate practitioners and promoting public education about the process

4. Refer to any existing professional guidance. Ideally, professional bodies such as the Royal Colleges would consider specific procedures such as fibreoptic intubation and issue precise recommendations. Where such guidance does not exist, reference should be made to other bodies' advice or even to senior colleagues who understand the issues

5. Consider any alternatives. The 'default' position should be full explanation and consent unless this is impractical and associated with wider harms. It would be advisable to record one's decision in the patient's notes when there is any doubt or disagreement, particularly when specific consent is not sought

6. Educate medical and other staff, to raise awareness of these issues. 
Consider now another anaesthetist, routinely using fibreoptic intubation as his standard technique following extensive training. The risks have been minimized, patients can expect maximum benefit from the less traumatic technique, and future patients benefit from his maintaining his skills. Should specific consent be obtained? Professional guidance suggests not. ${ }^{17,19}$ In some instances, though, more detailed discussion of intubation may be required - e.g. if specific concerns are raised such as sore throat - but the fact that a particular method of intubation is to be used would not alter this requirement. All doctors must be sensitive to their patients' anxieties and be prepared to exercise judgment, in accordance with general guidance relating disclosure to individual patients. ${ }^{12,13,16}$ In practical terms, this would take place when the usual discussion of the details of the anaesthetic technique occurs preoperatively.

The same applies when supervising trainees; consultants are responsible for their patients' care and must ensure that the patient is not put at increased risk. Use of a particular technique as part of a routine procedure does not in itself necessitate full discussion, even though it could be argued that this might infringe autonomy. However, a procedure introduced purely for training (e.g. nasotracheal intubation when orotracheal intubation would be usual) merits separate consent. The Department of Health advises that patients should understand ' . . . the nature and purpose of the procedure'. ${ }^{13}$

This approach recognizes a continuum. At one extreme, the risks of procedures are so great (e.g. high frequency of serious complications) or the benefits so small (e.g. readily available alternatives) that they should be either avoided or done by the most experienced person available. At the other extreme, the harms are so small and the benefits so great that use of the experience to promote learning does not necessarily require separate consent. Clearly, judgment is required for those decisions which should not be left to trainees. The same principles apply to procedures performed purely for learning/maintaining skills, but the test should be harder - akin to non-therapeutic research. Since the procedure is not part of normal treatment, consent should always be sought. Furthermore, some risks are so great as to prohibit a procedure with or without the patient's consent.

Acknowledgment I am grateful to Dr M Popat, Dr M Jonas and Dr R Worthington for helpful comments. This article arose from discussions within the Difficult Airway Society and is based on a dissertation submitted for the degree of MA in Medical Ethics and Law, Keele University, for which I was partly supported by the Riverside Research Ethics Committee.

\section{REFERENCES}

1 General Medical Council. Maintaining Good Medical Practice. London: GMC, 1998

2 General Medical Council. Good Medical Practice, 3rd edn. London: GMC, 2001

3 Stringer KR, Bajenov S, Yentis SM. Training in airway management. Anaesthesia 2002;57:967-83

4 Bray JK, Yentis SM. Attitudes of patients and anaesthetists to informed consent for specialist airway techniques. Anaesthesia 2002;57:1012-15

5 Jagsi R, Lehmann LS. The ethics of medical education. BMJ 2004;329:332-4

6 Berger JT, Rosner F, Cassell EJ. Ethics of practising medical procedures on newly dead and nearly dead patients. J Gen Intern Med 2002;17:774-8

7 Singer PA. Intimate examinations and other ethical challenges in medical education. BMJ 2003;326:62-3

8 Chikwe J, de Souza AC, Pepper JR. No time to train the surgeons. BMJ 2004;328:418-19

9 Sim DJ, Wrigley SR, Harris S. Effects of the European Working Time Directive on anaesthetic training in the United Kingdom. Anaesthesia 2004;59:781-4

10 Gillon R. 'The patient's interests always come first'? Doctors and society. BMJ 1986;292:398-400

11 Gillon R. Ethics needs principles - four can encompass the rest - and respect for autonomy should be "first among equals". J Med Ethics 2003;29:307-12

12 General Medical Council. Seeking Patients' Consent: the Ethical Considerations. London: GMC, 1998

13 Department of Health. Reference Guide to Consent for Examination or Treatment. London: DoH, 2001

14 Department of Health. Building on the Best: Choice, Responsiveness and Equity in the NHS. London: Stationery Office, 2003

15 Jones MA. Informed consent and other fairy stories. Med Law Rev 1999; 7:103-34

16 Department of Health. Good Practice in Consent Implementation Guide: Consent for Examination or Treatment. London: DoH, 2001

17 Association of Anaesthetists of Great Britain and Ireland. Information and Consent for Anaesthesia. London: AAGBI, 1999

18 Davis v Barking, Havering and Brentwood Health Authority [1993] 4 Med LR 85

19 Royal College of Anaesthetists [www.rcoa.ac.uk/index.asp? PageID=142] Accessed 5 April 2005

20 UK Clinical Ethics Network [www.ethics-network.org.uk/what.htm] Accessed 5 April 2005

21 Dan-Cohen M. Conceptions of choice and conceptions of autonomy. Ethics 1992;102:221-43

22 General Medical Council. Confidentiality: Protecting and Providing Information. London: GMC, 2004

23 Department of Health [www.dh.gov.uk/assetRoot/04/06/63/84/ 04066384.pdf] Accessed 7 December 2004

24 Waterbury JT. Refuting patients' obligations to clinical training: a critical analysis of the arguments for an obligation of patients to participate in the clinical education of medical students. Med Ed 2001;35:286-94

25 Callahan C. Principlism and communitarianism. J Med Ethics 2003;29:287-91

26 Draper H, Sorrell T. Patients' responsibilities in medical ethics. Bioethics 2002;16:335-52

27 Department of Health. Your Guide to the NHS. London DoH, 2001

28 Vinicky JK, Conners RB, Leader R, Nash JD. Patients as "subjects" or "objects"' in residency education? J Clin Ethics 1991;2:25-41

29 Van Dam S, Welie JVM. Requirement-driven dental education and the patient's right to informed consent. J Am Coll Dentists 2001;68:40-7 